\title{
Advanced Three-Dimensional Culture of Equine Intestinal Epithelial Stem Cells
}

\author{
A. Stieler Stewart, J. M. Freund, and L. M. Gonzalez \\ Department of Clinical Sciences, College of Veterinary Medicine, North Carolina State University, \\ Raleigh, NC 27607, USA
}

\section{Summary}

Background-Intestinal epithelial stem cells are critical to epithelial repair following gastrointestinal injury. The culture of intestinal stem cells has quickly become a cornerstone of a vast number of new research endeavours that range from determining tissue viability to testing drug efficacy for humans. This study aims to describe the methods of equine stem cell culture and highlights the future benefits of these techniques for the advancement of equine medicine.

Objectives-To describe the isolation and culture of small intestinal stem cells into threedimensional (3D) enteroids in horses without clinical gastrointestinal abnormalities.

\section{Study design-Descriptive study.}

Methods-Intestinal samples were collected by sharp dissection immediately after euthanasia. Intestinal crypts containing intestinal stem cells were dissociated from the underlying tissue layers, plated in a 3D matrix and supplemented with growth factors. After several days, resultant 3D enteroids were prepared for immunofluorescent imaging and polymerase chain reaction (PCR) analysis to detect and characterise specific cell types present. Intestinal crypts were cryopreserved immediately following collection and viability assessed.

Results-Intestinal crypts were successfully cultured and matured into 3D enteroids containing a lumen and budding structures. Immunofluorescence and PCR were used to confirm the existence of stem cells and all post-mitotic, mature cell types, described to exist in the horse intestinal epithelium. Previously frozen crypts were successfully cultured following a freeze-thaw cycle.

*Corresponding author Lmgonza4@ncsu.edu.

DR. LIARA M GONZALEZ (Orcid ID : 0000-0003-3972-2812)

OLUC Plan FLN, Olympus, Tokyo, Japan.

Authors' declarations of interest

No competing interests have been declared.

Ethical animal research

Procedures were approved by the North Carolina State University Institutional Care and Use Committee. Intestinal samples were obtained with the consent of the owners.

Authorship

L. Gonzalez contributed to the study design, study execution, data analysis and interpretation, preparation of the manuscript and final approval of the manuscript. A. Stewart contributed to the study design, study execution, data analysis and interpretation, preparation of the manuscript and final approval of the manuscript. J. Freund contributed to the study design, execution and final approval of the manuscript. 
Main limitations-Tissues were all derived from normal horses. Application of this technique for the study of specific disease was not performed at this time.

Conclusions-The successful culture of equine intestinal crypts into 3D "mini-guts" allows for ex vivo studies of the equine intestine. Additionally, these results have relevance to future development of novel therapies that harness the regenerative potential of equine intestine in horses with gastrointestinal disease (colic).

\section{Keywords}

horse; stem cell; 3D culture; intestine; enteroid; organoid

\section{Introduction}

Colic remains a major cause of morbidity and death in horses. Previous reports concluded that colic seconds old age as the leading cause of death in horses [1]. Death of these patients often results from breakdown of the intestinal mucosal barrier. This barrier is lined by a single layer of columnar cells, responsible for transporting nutrients, protecting the underlying tissues and self-renewal [2]. The small intestinal epithelium is composed of villi that extend into the lumen and are lined by differentiated, post-mitotic cell types, and the crypts of Lieberkühn that contain undifferentiated stem cells interspersed with Paneth cells and partially-differentiated transit amplifying cells [3]. Current literature proposes two populations of intestinal stem cells that co-exist in the crypt base including (1) active crypt base columnar cells and (2) reserve/quiescent stem cells that are activated upon injury and preferentially reside at a position four cells above the crypt base [4,5]. The intestinal stem cells are responsible for creating a new epithelial mucosal lining every 5-7 days and only differentiate into cells of intestinal epithelial lineage, unlike mesenchymal stem cells that can give rise to multiple tissue types [4,6].

Recent discoveries in the field of stem cell biology have demonstrated the growth potential and differentiation of stem cells in culture from murine, porcine and human intestinal epithelium $[7,8,9]$. These culture systems have been used as models of tissue morphogenesis, stem cell lineage selection, tissue plasticity and bidirectional signaling of stem cells and their niche [10]. Studies utilising these cultures to determine the impact of injury and regenerative response of stem cells remain limited. Understanding stem cell dynamics as well as inter- and intra- cellular interactions is critical in order to harness the regenerative potential of these resident stem cells as novel therapeutic targets to improve outcome in cases of severe colic $[11,12,13]$.

At this time, limited work has been done in the field of equine intestinal stem cell culture $[14,15]$. The capacity of intestinal stem cells to contribute to mucosal repair make them a key target for researchers.

The objective of the study reported here was to describe the isolation, culture and differentiation of intestinal crypts into 3D enteroids from horses without clinical gastrointestinal abnormalities. Our aim was to successfully grow enteroids in culture and identify and distinguish stem cells, partially differentiated cells, and postmitotic epithelial 
cells by means of histologic evaluation, immunofluorescence and polymerase chain reaction (PCR).

\section{Materials and Methods}

\section{Animals and Sample Collection}

Tissues were obtained from 5 healthy horses of various breeds ( 3 geldings, 2 mares) that were euthanised for reasons unrelated to this study. Horses ranged from 5-14 years of age. Immediately following euthanasia, several $20 \mathrm{~cm}$ sections of mid-jejunum were removed through a celiotomy incision and immediately processed as described.

\section{Crypt Isolation, Enteroid Culture and Analysis}

The excised jejunum was washed in cold phosphate buffered saline solution (PBS) and opened longitudinally. The intestine was sectioned into smaller squares measuring $1-2 \mathrm{~cm}$ in diameter. The layers of the intestine were not separated prior to incubation. Several small pieces of tissue were incubated for $30 \mathrm{~min}$ in a $50 \mathrm{ml}$-conical tube with PBS containing 30

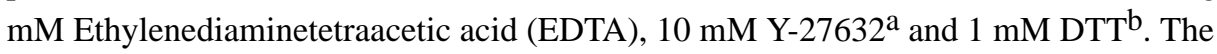
conical tube, in addition to vigorous shaking every $5 \mathrm{~min}$, was kept on ice and on an orbital shaking platform moving at $60 \mathrm{rpm}$. Tissue pieces were transferred into a $37^{\circ} \mathrm{C}$ pre-warmed PBS solution containing $30 \mathrm{mM}$ EDTA and $10 \mathrm{mM} \mathrm{Y-27632.} \mathrm{The} \mathrm{tissue} \mathrm{was} \mathrm{incubated} \mathrm{in}$ this solution at $37^{\circ} \mathrm{C}$ for $10 \mathrm{~min}$ and shaken vigorously to help mobilise the crypt/villi units. Following this incubation, the tissues were placed in an ice-cold PBS wash containing $1 \mathrm{X}$ antibiotic-antimycotic ${ }^{\mathrm{c}}$ for $5 \mathrm{~min}$. Tissue was then transferred into additional washes and shaken until crypt/villi units were seen with minimal background debris. Following the final wash, the remnant intestine was removed from the solution and the solution filtered using a 100-micron sterile cell strainer ${ }^{d}$ to remove the villi. A desired crypt yield of approximately 50 crypts $/ 50 \mu \mathrm{L}$ was determined by examining several $50 \mu \mathrm{L}$ aliquots at $10 \mathrm{X}$. The crypts were then pelleted in preparation of plating.

The pelleted crypts were re-suspended directly into growth factor reduced Matrigel ${ }^{\mathrm{e}}$ supplemented with $100 \mathrm{ng} / \mathrm{mL}$ recombinant human $\operatorname{Noggin}^{\mathrm{f}}, 500 \mathrm{ng} / \mathrm{mL}$ recombinant human R-Spondin $\mathrm{g}, 50 \mathrm{ng} / \mathrm{mL}$ recombinant human $\mathrm{EGF}^{\mathrm{c}}, 100 \mathrm{ng} / \mathrm{mL}$ recombinant human Wnt $3 \mathrm{a}^{\mathrm{g}}$, $10 \mathrm{mM}$ Y-27632, $10 \mathrm{mM} \mathrm{SB} 202190^{\mathrm{b}}, 500 \mathrm{nM}$ LY2157299 and $2.5 \mu \mathrm{M}$ glycogen synthase kinase 3 inhibitor (GSK3i, CHIR99021). Between 25-50 crypts were plated in $50 \mu \mathrm{L}$ of matrigel on a 24 well plate ${ }^{\mathrm{d}}$. After allowing the matrix to polymerise for $30 \mathrm{~min}$ at $37^{\circ} \mathrm{C}$, each well was overlaid with $500 \mathrm{~mL}$ of Advanced DMEM/F12 containing the supplements 1X N-2 supplement ${ }^{\mathrm{c}}, 1$ X B-27 supplement minus vitamin $\mathrm{A}^{\mathrm{c}}$, 1X Glutamax ${ }^{\mathrm{c}}, 100 \mathrm{mg} / \mathrm{mL}$ penicillin/streptomycin and $1 \mathrm{mM}$ Hepes buffer ${ }^{\mathrm{c}}$. Growth factors were added to the media

\footnotetext{
aSelleck Chemicals, Houston, Texas, USA.

$\mathrm{b}_{\text {Sigma-Aldrich, St. Louis, Missouri, USA. }}$

${ }^{c}$ Life Technologies Corporation, Carlsbad, California, USA.

$\mathrm{d}$ Corning Incorporated, Corning, New York, USA.

$\mathrm{e}_{\mathrm{BD}}$ Bioscience, San Jose, California, USA.

$\mathrm{f}_{\text {PeproTech, Rocky Hill, New Jersey, USA. }}$

$\mathrm{g}_{\mathrm{R} \& D}$ Systems Inc, Minneapolis, Minnesota, USA.
} 
$48 \mathrm{~h}$ after plating and subsequent $48 \mathrm{~h}$ intervals. The entire volume of media was changed 96 $\mathrm{h}$ following plating and every subsequent $96 \mathrm{~h}$ interval.

Enteroid plating efficiency was calculated by counting the number of enterospheres or enteroids formed every 24 hours divided by the starting number of crypts plated in each matrigel matrix.

\section{Subculture technique}

Passage of enteroids was attempted once the enteroids demonstrated significant budding and growth between 7-10 days post plating. To passage enteroids, the matrigel matrix was first depolymerised nonenzymatically following a PBS rinse in cell recovery solution ${ }^{\mathrm{d}}$ on ice for $30 \mathrm{~min}$. The resultant enteroids and recovery solution were collected and centrifuged at 200$300 \mathrm{G}$ for $5 \mathrm{~min}$. The supernatant was removed, the pellet resuspended in PBS, passed through a 27 -gauge needle ${ }^{\mathrm{h}}$ and spun down at $200-300 \mathrm{G}$ for $5 \mathrm{~min}$. The pellet was then resuspended in Matrigel and plated as above.

\section{Cryo-preservation of Equine Crypts}

To assess freezing as an option for long-term storage, freshly isolated equine jejunal crypts were suspended in $1 \mathrm{ml}$ freeze- preservation medium consisting of $10 \%$ dimethylsulfoxide in 1X DMEM/F12 culture medium with no growth factors and were frozen slowly over 12-18 hours using a cryo freezing container ${ }^{\mathrm{i}}$ placed in a $-80^{\circ} \mathrm{C}$ freezer. This method is designed to achieve a rate of cooling close to $-1^{\circ} \mathrm{C} /$ minute, the optimal rate for cell preservation.

Following removal from the $-80^{\circ} \mathrm{C}$ freezer, the tubes were stored in liquid nitrogen. To thaw, cryopreservation tubes were obtained from liquid nitrogen storage and warmed in a $37^{\circ} \mathrm{C}$ water bath. The tubes were centrifuged to pellet the crypts at $200-300 \mathrm{G}$ for 5 minutes. The freezing media was removed and the crypt pellet was resuspended in cooled matrigel and plated as above on a 24 well plate.

\section{Enteroid Immunofluorescence Analyses}

Fixed sections-Crypts were plated onto a polystyrene plate with transwell insert ${ }^{\mathrm{d}}$ and removed from the incubator at 7 days of development. Enteroids were fixed overnight in formalin. The transwell filter and matrigel plug were removed from the plate insert, covered in agarose, embedded in paraffin and sectioned ( $\sim-8 \mu \mathrm{m}$ thickness). Deparaffinisation was performed using a modified protocol with xylene, ethanol and peroxidase. Heat induced epitope retrieval was performed when necessary by heating in reveal decloaker solution ${ }^{j}$ to $120^{\circ} \mathrm{C}$ for $30 \mathrm{~s}$ and then $90^{\circ} \mathrm{C}$ for $10 \mathrm{~s}$ inside a pressure cooker ${ }^{\mathrm{k}}$. Slides were allowed to cool to room temperature for $20 \mathrm{~min}$ prior to staining. Enteroids were permeabilised in a $0.3 \%$ Triton X-100 PBS solution for 20 min and then blocked in protein block solution ${ }^{\mathrm{k}}$ for 30 min. Primary antibodies labeling individual cell types were applied at concentrations previously published [16], and incubated overnight at $4^{\circ} \mathrm{C}$. Additional primary antibodies included anti-Lysozyme and anti-Ki67 for Paneth cells and proliferating cell populations,

\footnotetext{
$\mathrm{h}_{\mathrm{BD}}$, Franklin Lakes, New Jersey, USA.

iThermo Fischer Scientific, Waltham, Massachusetts, USA.

$\mathrm{j}_{\text {Biocare Medical, Concord, California, USA. }}$

k Dako, Agilent Technologies, Santa Clara, California, USA.
} 
respectively. All secondary staining was performed with Cy3, Alexa488 and Alexa 647 conjugated antibodies diluted 1:500 in antibody diluent ${ }^{\mathrm{k}}$ incubated at room temperature for 45 min. Nuclei were marked with bisbenzamide Hoechst 33258 nuclear stain ${ }^{b}$ diluted 1:1000 in PBS and applied for 5 min at room temperature.

Background staining was negligible as determined by nonspecific IgG staining. Images were captured on an inverted fluorescence microscope ${ }^{1}$ fitted with a monochrome digital camera ${ }^{\mathrm{m}}$ and colour camera ${ }^{\mathrm{n}}$. The objective lenses used were X10, X20 and X40 with numerical apertures of $0.3,0.45$ and 0.6 , respectively.

Whole Mount Staining-After culturing, the enteroids were removed from the incubator at 5-7 days of development. The enteroids were whole mounted and stained using a modified protocol from StemCell Technologies $\mathrm{p}$. Briefly, the stem cell media was gently aspirated. Following a wash in room temperature PBS, enteroids were fixed in the Matrigel using room temperature $4 \%$ paraformaldehyde (PFA). Following two washes in PBS, $0.1 \%$ Triton X-100 was applied. The enteroids were blocked using 5\% BSA. Primary antibody was added and left overnight at $4^{\circ} \mathrm{C}$. Dilutions for functional antibodies were increased compared to those previously published and are provided (Table 1). All secondary staining was performed with $\mathrm{Cy} 3$ and Alexa488 conjugated antibodies ${ }^{\mathrm{i}}$ diluted 1:250 in antibody diluent incubated for 45 minutes at approximately $21^{\circ} \mathrm{C}$. Mounts were counterstained with bisbenzamide Hoechst $33258^{\mathrm{b}}$ nuclear stain (diluted 1:500 in PBS solution).

PCR - The jejunal mucosa was physically separated from seromuscular layers by scraping with a glass slide and was placed in RNAse free microcentrifuge tubes and immediately placed in liquid nitrogen. Enteroids grown in matrigel were collected using Cell Recovery solution. Enteroids were collected into an RNAse free microtube and placed in liquid nitrogen. Jejunal scrapings and enteroids were then stored at $-80^{\circ} \mathrm{C}$ until use. Total RNA from jejunal tissue and enteroids was extracted using the Qiagen RNeasy Minikit $\mathrm{q}$. Yield and quality of the extracts were determined by measuring absorbance at 260 and $280 \mathrm{~nm}^{\mathrm{r}}$. The ratio of absorbance at 260:280 was between 2.02 and 2.09. $1 \mu \mathrm{g}$ of RNA was converted to cDNA using the iScript cDNA synthesis kit ${ }^{\mathrm{s}}$ and pooled. The cycle conditions were 5 min at $25^{\circ} \mathrm{C}$, cDNA synthesis at $42^{\circ} \mathrm{C}$ for $30 \mathrm{~min}$, denaturation at $85^{\circ} \mathrm{C}$ for $5 \mathrm{~min}$ and held at $4^{\circ} \mathrm{C}$. Primers were designed based on published sequences of horse target genes either manually or using the National Center for Biotechnology Information (NCBI) online primer design tool ${ }^{t}$. Specific target sequences, cell type and expected product sizes are provided (Table 2). The specificity of the primers was checked using the NCBI online Blast tool ${ }^{\mathrm{v}}$. RTPCR was performed utilising the iTaq Universal SYBR green Supermix ${ }^{\mathrm{s}}$. The StepOnePlus real time PCR system ${ }^{\mathrm{c}}$ was used. Cycle parameters included polymerase activation and

lOlympus IX83, Tokyo, Japan.

mORCA-flash 4.0, Hamamatsu, Japan.

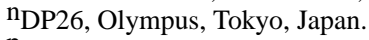

PStemCell Technologies, Vancouver, British Columbia, Canada.

qQiagen Inc, Valencia, California, USA.

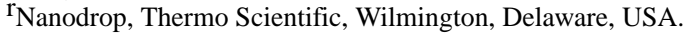

SBio-Rad, Hercules, California, USA.

tPrimerBlast, NCBI, Bethesda, Maryland, USA.

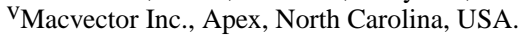


DNA denaturation at $95^{\circ} \mathrm{C}$ for $30 \mathrm{~s}$. Forty cycles of amplification were performed with a 15 $\mathrm{s}$ denaturation at $95^{\circ} \mathrm{C}$ and annealing/extension and plate read for $60 \mathrm{~s}$ at $60^{\circ} \mathrm{C}$. The melting curve analysis was performed at $65^{\circ} \mathrm{C}-95^{\circ} \mathrm{C}$ at $0.5^{\circ} \mathrm{C}$ increments, $5 \mathrm{~s}$ per step. Melting curves were checked to ensure consistent amplification of a single PCR product. Primer efficiency was calculated using the equation, Efficiency $=10^{\wedge}(-1 /$ slope $)-1$. Only primers with greater than $92 \%$ efficiency were considered acceptable. All primers were first validated using cDNA derived from normal equine jejunal samples.

Target Validation by Sequencing-RT-PCR amplicons were analysed on a $1.5 \%$ Agarose TE gel to assess size. Samples were sequenced ${ }^{\mathrm{u}}$ and the sequences were aligned to the gene target using the NCBI online Blast tool ${ }^{t}$ and MacVector alignment program ${ }^{\mathrm{v}}$ for validation.

\section{Results}

\section{In vitro culture of equine crypts}

Using a modified 3D culture environment similar to the culture conditions that support growth of porcine and mouse enteroids [7,9,17], within 24 hours of plating, equine crypts isolated from jejunal tissue formed enterospheres, a spherical structure with a clearly defined basement membrane and lumen and with an average diameter of $97.85 \pm 18.43 \mu \mathrm{m}$ (Fig 1A and B). Following two days of culture these structures began to bud. These structures persist, enlarge and by day 3 begin to convert into enteroids, more complex three dimensional structures with a clearly defined lumen, columnar epithelial cells and primitive crypt buds, and measure an average of $199.3 \pm 49.68 \mu \mathrm{m}$ in diameter (Fig 1C). Within 5 days, enteroids appear as large complex structures with multiple well defined crypt buds and an average diameter of $340.1 \pm 122.2 \mu \mathrm{m}$ (Fig 1D; Supplementary Item 1). Mean plating efficiency was $59.08 \pm 25.07 \%$ (Supplementary Item 2 ).

\section{Subculture of equine crypts}

Enteroids were successfully passaged using a 27 -gauge needle, replated and formed large budding structures by culture day 5 . However, despite effectively disrupting and re-plating the enteroids into single cells and small buds, expansion of the original population was minimal. A modification of the technique was therefore attempted without passage through a needle. Following centrifugation and removal of the cell recovery solution, the pellet was alternatively resuspended aggressively in the matrigel prior to re-plating. This modification resulted in an effective expansion of the original cell population with larger spheroid structures and budding noted in addition to small, single spheroids.

\section{Cryo-preservation of equine crypts}

Equine crypts that were frozen in liquid nitrogen for a range of 3 weeks to 4 months were successfully thawed and cultured as above in enteroid medium. Accurate enteroid counts were difficult to obtain as many of the plated crypts were fragmented at the time of plating resulting in increased background debris. Enterosphere formation was delayed 24-48 hours

uGENEWIZ, South Plainfield, New Jersey, USA. 
after a freeze-thaw cycle compared with untreated control crypt cultures but large budding enteroid structures were observed by culture day 7 (not shown).

\section{Detection of intestinal stem cells, cellular proliferation and specific epithelial cell types by immunofluorescence}

Assessment of cellular proliferation is essential for monitoring normal regenerative responses as well as those following injury. The protein Ki67 is a cellular marker for proliferation and is present in all stages of the cell cycle except rest $\left(\mathrm{G}_{0}\right)$ [18]. Within the enteroids, intestinal stem cells and a sub-population of transit amplifying cells were identified using antibodies against sex-determining region Y-box 9 (SOX9) [19,20] and KI67, respectively (Fig 2). Cells positive for both SOX9 and KI67 were found (colocalisation) indicating cells in a state of active proliferation or early stages of differentiation. Immunostaining for homeobox protein (HOPX), a marker for reserve stem cell populations in other species [9,21] was not detected. Additionally, antibodies for the stem cell biomarkers leucine-rich repeats and immunoglobulin-like domains 1 (LRIG1) [22] and leucine-rich repeat-containing G-protein coupled receptor 5 (LGR5) [23] did not cross react with the equine proteins and were not detected (data not shown).

Epithelial cells and post-mitotic cell types were also identified through immunofluorescent antibody staining. The baso-lateral borders of all epithelial cells were positive for $\beta$-catenin expression (Fig 3B). Epithelial cell adhesion molecule (EpCAM), a pan-epithelial transmembrane protein [24], demonstrated expression along the membrane of epithelial cells (Fig 3A). Secretory enteroendocrine cells were identified by immunofluorescence labeling of chromogranin A ( $\mathrm{CgA}$ ) [25] within the cytoplasm of a small number of cells distributed throughout the enteroid sections (Fig 4A). Expression of cytoplasmic mucin (MUC2) [26] was detected within goblet cells and the lumen of the developing enteroid (Fig 4B) and positive immunostaining for lysozyme (Lyz) was observed, indicating the presence of Paneth cells [27] (Fig 4C).

\section{Detection of specific epithelial cell types by PCR}

PCR confirmed the expression of intestinal stem cell target genes SOX9, HOPX, LRIG and $L G R 5$, and post-mitotic cell target genes $C G A$, sucrase isomaltase (SIM, a biomarker of absorptive enterocytes) [28], $L Y Z$ and $\underline{M U C 2}$ within 7-day enteroids (sequences provided in Table 2).

\section{Discussion}

In the present study, intestinal crypts containing intestinal stem cells from subjectively normal horse jejunum were successfully cultured, developing into mature, 3D enteroids containing post-mitotic cell types. This is the first report describing the development of equine crypts into complex intestinal "mini-guts" containing stem cells and differentiated, post-mitotic cell types. Mini-gut enteroids or organoids recapitulate the intestinal epithelium seen in vivo with a central lumen and outwardly budding crypt-like structures [29]. A preliminary abstract described successful isolation and plating of equine crypts from small intestine and large colon [14], while recent work confirmed successful growth of equine 
enteroids from the ileum [15]. Unlike these prior studies, we were able to demonstrate the successful development and maturation of isolated crypts into 3D enteroids along with the cellular characterisation, maintenance, and frozen storage of these cultures.

The results of this study confirmed the existence of intestinal stem cells, partiallydifferentiated transit-amplifying cells, and post-mitotic cell types within developing enteroids. In normal intestine, intestinal stem cells are localised to the crypt base and differentiate as they move towards the intestinal lumen resulting in progressive loss of SOX9 expression. This was appreciated by immunofluorescent co-localisation results that demonstrated the co-localisation of a general marker of cellular proliferation (Ki67) with SOX9 indicating a cell type of minimal to no differentiation whereas Ki67 staining alone indicates a cell type that is proliferating but has lost its stemness. Several approaches to identify equine epithelial cell types were pursued because of the innate advantages and disadvantages of each technique. Similar to other studies, antibody-based assays alone failed to positively identify all intestinal epithelial cell types $[9,16]$. The antibodies that were used were commercially derived and raised against proteins in species other than horses. Many cellular biomarkers were conserved between species, as indicated by cross-reactivity of several antibodies with equine proteins in this study. A previous study helped to establish the existence and normal distribution of cell types within the equine small and large intestinal mucosa and the reagents and tools currently available [16]. Successful amplification of known gene cellular biomarkers was further used to characterise and confirm the existence of all known cell types that exist in the equine intestinal epithelium.

The methods described in this paper provide the foundation for future equine in vitro studies focusing on the gastrointestinal tract. Limited work has been performed utilising these techniques in veterinary patients. Successful intestinal organoid growth has been demonstrated in pigs $[9,17]$ and dogs $[15,30,31]$. There are many benefits to ex vivo intestinal organoid culture in the research setting. These organoids may serve as a model for stem cell behaviour and biology, and can be used as a screening tool to investigate the effects of different drugs, hormones and pathogenic organisms on normal and diseased patient samples [5,32]. Furthermore, the lumen of intestinal organoids is intact, which allows for microinjection and the study of pathogen-epithelial cell interaction [33,34]. Our study was limited in that we did not investigate the functional capacity of the cultured enteroids. Functional assays including the study of tight junction proteins and measurement of transport function, have been described in other species. Future work should focus on these techniques in equine intestinal stem cell culture [35,36,37].

As techniques become more advanced and our understanding of these mini-gut cultures continues to grow, the potential remains for the utilisation of these cells in tissue healing and tissue transplantation. In research conditions, colonic organoids were successfully engrafted into superficially damaged mouse colon following transplant [38]. More recently, human intestinal organoids were successfully transplanted and matured in the kidney capsule of a mouse [39]. Transplanted tissues demonstrated digestive function and responded to circulating humoral factors following ileocecal resection. Three-dimensional organoid cultures have also been successfully grown from a variety of other tissues in the mouse and human including the stomach, liver, pancreas [29] and brain [40]. These advances in the 
field of stem cell biology demonstrate the range of techniques that can be performed and the future potential of these culture systems to develop novel therapeutic interventions. To date, none of these advances have been investigated in an equine culture model. However, the translational techniques demonstrated in other species will aid in the advancement of equine 3D cell culture. This study provides the first major step toward utilising this technology to advance the field specific to equine medicine as well as provides the foundation for using the horse as a model to study stem-cell driven intestinal regeneration.

\title{
Supplementary Material
}

Refer to Web version on PubMed Central for supplementary material.

\section{Acknowledgments}

\begin{abstract}
Sources of funding
This work was funded by an NIH Special Emphasis Research Career Award (SERCA, K01OD0199, LMG) as well as the Comparative Medicine and Translational Research Training Program (NIH Ruth L. Kirschstein NRSA, 4T32OD011130-09, ASS). The content is solely the responsibility of the authors and does not necessarily represent the official views of the NIH. The funders had no role in study design, data collection and analysis, decision to publish, or preparation of the manuscript.

The authors gratefully acknowledge Shelby Grillo, Madison Voigt and Cecilia Kucera for their assistance in primer design and method validation. We also wish to thank Leandi Kruger for her assistance with sample fixation.
\end{abstract}

\section{Abbreviations Used}

\begin{tabular}{ll} 
PCR & Polymerase chain reaction \\
HIER & Heat induced epitope retrieval \\
MUC2 & Mucin 2 \\
PCNA & Proliferating cell nuclear antigen \\
SOX9 & Sex determining region Y-box 9 \\
EPCAM & Epithelial adhesion molecule \\
CGA & Chromogranin A \\
SIM & Sucrase isomaltase \\
LYZ & Lysozyme \\
HOPX & Homeobox protein \\
LGR5 & Leucine rich repeat containing G-protein coupled receptor 5 \\
LRIG1 & Leucine rich repeats and immunoglobulin-like domains 1 \\
EPCAM & Epithelial cell adhesion molecule \\
\hline
\end{tabular}




\section{References}

1. USDA APHIS Veterinary Services Center for Epidemiology and Animal Health. Part I: Baseline reference of equine health and management. CO, Fort Collins: 2005.

2. Kararli TT. Comparison of the gastrointestinal anatomy, physiology, and biochemistry of humans and commonly used laboratory animals. Biopharm Drug Dispos. 1995; 16:351-380. [PubMed: 8527686]

3. Cheng H, Leblond CP. Origin, differentiation and renewal of the four main epithelial cell types in the mouse small intestine. V Unitarian Theory of the origin of the four epithelial cell types. Am J Anat. 1974; 141:537-561. [PubMed: 4440635]

4. Gonzalez LM. The mother of a gut cell: Intestinal epithelial stem cells. Equine Vet Educ. 2015; 27:559-560.

5. Leushacke M, Barker N. Ex vivo culture of the intestinal epithelium: strategies and applications. Gut. 2014; 63:1345-1354. [PubMed: 24841573]

6. Sancho E, Batlle E, Clevers H. Live and let die in the intestinal epithelium. Curr Opin Cell Biol. 2003; 15:763-770. [PubMed: 14644203]

7. Sato T, Vries RG, Snippert HJ, van de Wetering M, Barker N, Stange DE, van Es JH, Abo A, Kujala P, Peters PJ, Clevers H. Single Lgr5 stem cells build crypt-villus structures in vitro without a mesenchymal niche. Nature. 2009; 459:262-265. [PubMed: 19329995]

8. Sato T, Stange DE, Ferrante M, Vries RG, Van Es JH, Van den Brink S, Van Houdt WJ, Pronk A, Van Gorp J, Siersema PD, Clevers H. Long-term expansion of epithelial organoids from human colon, adenoma, adenocarcinoma, and Barrett's epithelium. Gastroenterology. 2011; 141:17621772. [PubMed: 21889923]

9. Gonzalez LM, Williamson I, Piedrahita JA, Blikslager AT, Magness ST. Cell lineage identification and stem cell culture in a porcine model for the study of intestinal epithelial regeneration. PLoS One. 2013; :8.doi: 10.1371/journal.pone.0066465

10. Kretzschmar K, Clevers H. Organoids: Modeling Development and the Stem Cell Niche in a Dish. Dev Cell. 2016; 38:590-600. [PubMed: 27676432]

11. Markel TA, Crisostomo PR, Lahm T, Novotny NM, Rescoria FJ, Tector AJ, Meldrum DR. Stem cells as a potential future treatment of pediatric intestinal disorders. J Pediatr Surg. 2008; 43:19531963. [PubMed: 18970924]

12. Neal MD, Richardson WM, Sodhi CP, Russo AM, Hackam DJ. Intestinal stem cells and their roles during mucosal injury and repair. J Surg Res. 2011; 167:1-8. [PubMed: 20599211]

13. Quante M, Wang TC. Stem cells in gastroenterology and hepatology. Nat Rev Gastroenterol Hepatol. 2009; 6:724-737. [PubMed: 19884893]

14. Jacobs CC, Southwood LL, Lindborg S. Development of an in-vitro three-dimensional culture system for equine gastrointestinal crypts. Vet Surg. 2013; 42:E13.

15. Powell RH, Behnke MS. WRN conditioned media is sufficient for in vitro propagation of intestinal organoids from large farm and small companion animals. Biol Open. 2017; 6:698-705. [PubMed: 28347989]

16. Gonzalez LM, Kinnin LA, Blikslager AT. Characterization of discrete equine intestinal epithelial cell lineages. Am J Vet Res. 2015; 76:358-366. [PubMed: 25815577]

17. Khalil HA, Lei NY, Brinkley G, Scott A, Wang J, Kar UK, Jabaji ZB, Lewis M, Martin MG, Dunn JC, Stelzner MG. A novel culture system for adult porcine intestinal crypts. Cell Tissue Res. 2016; 365:123-134. [PubMed: 26928041]

18. Scholzen T, Gerdes J. The Ki-67 protein: from the known and the unknown. J Cell Physiol. 2000; 182:311-322. [PubMed: 10653597]

19. Gracz AD, Ramalingam S, Magness ST. Sox9 expression marks a subset of CD24-expressing small intestine epithelial stem cells that form organoids in vitro. Am J Physiol Gastrointest Liver Physiol. 2010; 298:G590-600. [PubMed: 20185687]

20. Formeister EJ, Sionas AL, Lorance DK, Barkley CL, Lee GH, Magness ST. Distinct SOX9 levels differentially mark stem/progenitor populations and enteroendocrine cells of the small intestine epithelium. Am J Physiol Gastrointest Liver Physiol. 2009; 296:G1108-1118. [PubMed: 19228882] 
21. Takeda N, Jain R, LeBoeuf MR, Wang Q, Lu MM, Epstein JA. Interconversion between intestinal stem cell populations in distinct niches. Science. 2011; 334:1420-1424. [PubMed: 22075725]

22. Powell AE, Wang Y, Li Y, Pouline EJ, Means AL, Washington MK, Higginbotham JN, Juchheim A, Prasad N, Levy SE, Guo Y, Shyr Y, Aronow BJ, Haigis KM, Franklin JL, Coffey RJ. The panErbB negative regulator Lrig1 is an intestinal stem cell marker that functions as a tumor suppressor. Cell. 2012; 149:146-158. [PubMed: 22464327]

23. Barker N, van Es JH, Kuipers J, Kujala P, van den Born M, Cozijnsen M, Haegebarth A, Korving J, Begthel H, Peters PJ, Clevers H. Identification of stem cells in small intestine and colon by marker gene Lgr5. Nature. 2007; 449:1003-1007. [PubMed: 17934449]

24. Trzpis M, McLaughlin PM, de Leij LM, Harmsen MC. Epithelial cell adhesion molecule: more than a carcinoma marker and adhesion molecule. Am J Pathol. 2007; 171:386-395. [PubMed: 17600130]

25. Portela-Gomes GM, Stridsberg M, Johansson H, Grimelius L. Complex co-localization of chromogranins and neurohormones in the human gastrointestinal tract. J Histochem Cytochem. 1997; 45:815-822. [PubMed: 9199667]

26. Johansson ME, Sjovall H, Hansson GC. The gastrointestinal mucus system in health and disease. Nat Rev Gastroenterol Hepatol. 2013; 10:352-361. [PubMed: 23478383]

27. Farin HF, Van Es JH, Clevers H. Redundant sources of Wnt regulate intestinal stem cells and promote formation of Paneth cells. Gastroenterology. 2012; 143:1518-1529. [PubMed: 22922422]

28. Rodriguez IR, Taravel FR, Whelan WJ. Characterization and function of pig intestinal sucraseisomaltase and its separate subunits. Eur J Biochem. 1984; 143:575-582. [PubMed: 6479163]

29. Date S, Sato T. Mini-gut organoids: reconstitution of the stem cell niche. Annu Rev Cell Dev Biol. 2015; 31:269-289. [PubMed: 26436704]

30. Agopian VG, Chen DC, Avansino JR, Stelzner M. Intestinal stem cell organoid transplantation generates neomucosa in dogs. J Gastrointest Surg. 2009; 13:971-982. [PubMed: 19165549]

31. Meneses AMC, Schneeberger K, Kruitwagen HS, Penning L, van Steenbeek F, Burgener I, Spee B. Intestinal Organoids-Current and Future Applications. Veterinary Sciences. 2016; :3.doi: 10.3390/vetsci3040031

32. Dedhia PH, Bertaux-Skeirik N, Zavros Y, Spence JR. Organoid Models of Human Gastrointestinal Development and Disease. Gastroenterology. 2016; 150:1098-1112. [PubMed: 26774180]

33. Wilson SS, Tocchi A, Holly MK, Parks WC, Smith JG. A small intestinal organoid model of noninvasive enteric pathogen-epithelial cell interactions. Mucosal Immunol. 2015; 8:352-361. [PubMed: 25118165]

34. Nigro G, Hanson M, Fevre C, Lecuit M, Sansonetti PJ. Intestinal Organoids as a Novel Tool to Study Microbes-Epithelium Interactions. Methods Mol Biol. 2016; doi: 10.1007/7651_2016_12

35. Zhang YG, Wu S, Xia Y, Sun J. Salmonella-infected crypt-derived intestinal organoid culture system for host-bacterial interactions. Physiol Rep. 2014; :2.doi: 10.14814/phy2.12147

36. Zachos NC, Kovbasnjuk O, Foulke-Abel J, In J, Blutt SE, de Jonge HR, Estes MK, Donowitz M. Human Enteroids/Colonoids and Intestinal Organoids Functionally Recapitulate Normal Intestinal Physiology and Pathophysiology. J Biol Chem. 2016; 291:3759-3766. [PubMed: 26677228]

37. Kovbasnjuk O, Zachos NC, In J, Blutt SE, de Jonge HR, Estes MK, Donowitz M. Human enteroids: preclinical models of non-inflammatory diarrhea. Stem Cell Res Ther. 2013; 4(Suppl 1):S3. [PubMed: 24564938]

38. Yui S, Nakamura T, Sato T, Nemoto Y, Mizutani T, Zheng X, Ichinose S, Nagaishi T, Okamoto R, Tsuchiya K, Clevers H, Watanabe M. Functional engraftment of colon epithelium expanded in vitro from a single adult Lgr5(+) stem cell. Nat Med. 2012; 18:618-623. [PubMed: 22406745]

39. Watson CL, Mahe MM, Munera J, Howell JC, Sundaram N, Poling HM, Schwitzer JI, Vallance JE, Mayhew CN, Sun Y, Grabowski G, Finkbeiner SR, Spence JR, Shroyer NF, Wells JM, Helmrath MA. An in vivo model of human small intestine using pluripotent stem cells. Nat Med. 2014; 20:1310-1314. [PubMed: 25326803]

40. Yin X, Mead BE, Safaee H, Langer R, Karp JM, Levy O. Engineering Stem Cell Organoids. Cell Stem Cell. 2016; 18:25-38. [PubMed: 26748754]

Equine Vet J. Author manuscript; available in PMC 2019 March 01. 

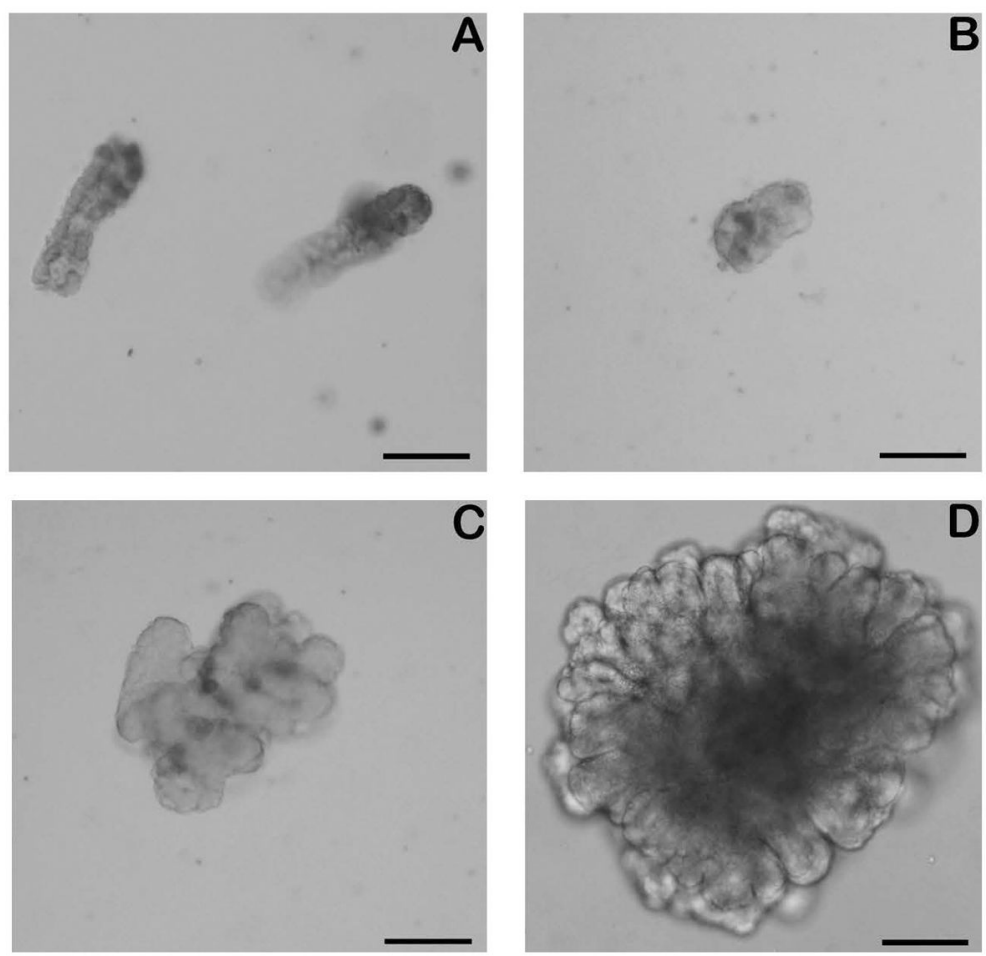

Fig 1.

In vitro culture of equine crypts. The in vitro isolation, growth and maintenance of enteroids derived from equine intestinal crypts are shown. On day of collection (Day 0, panel A), crypts maintain their morphological appearance. Enterospheres first develop (Day 1, panel B) and progressively enlarge to form complex structures with a pseudolumen and crypt like structures (Day 3, panel C; Day 5, panel D). Scale Bar $100 \mu \mathrm{m}$. 
sox9

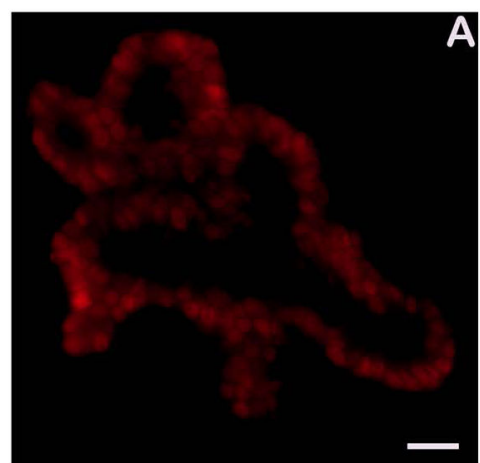

SOX9/K167

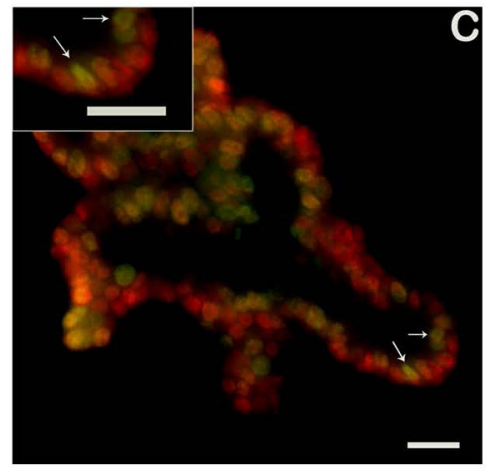

KI67

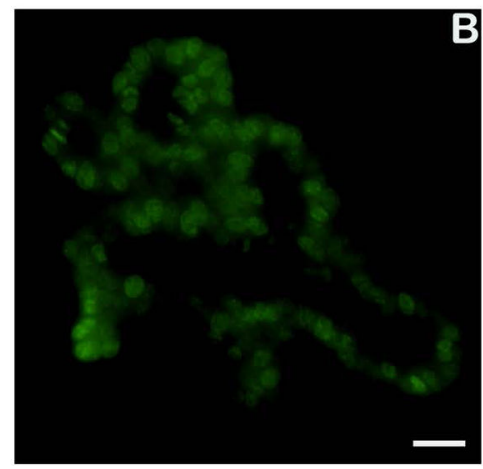

DAPI

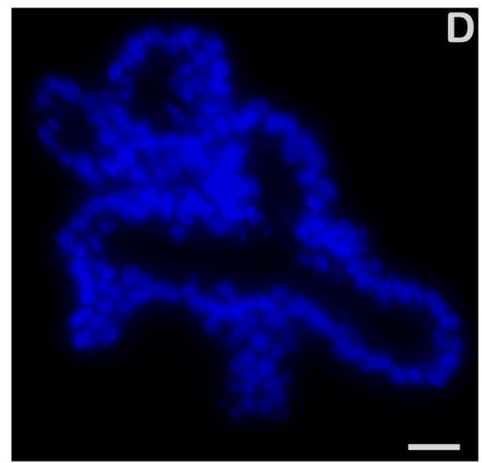

Fig 2.

Markers to identify proliferating cell populations. Identification of intestinal stem and transit amplifying cells in equine enteroids are shown. Immunostaining for SOX9 (red, panel A and C), a transcription factor that is primarily expressed in active intestinal stem cells and transitamplifying progenitor cells is localised to the nuclei of cells along the primitive enteroid buds. Colocalisation with a general marker of proliferation (Ki67+, green, panel B and C) is also seen. Digital magnification demonstrating colocalisation (yellow) of SOX9 (red) and $\mathrm{Ki} 67$ (green) is provided. Nuclei, blue (panel D). Insert scale bar $20 \mu \mathrm{m}$. 

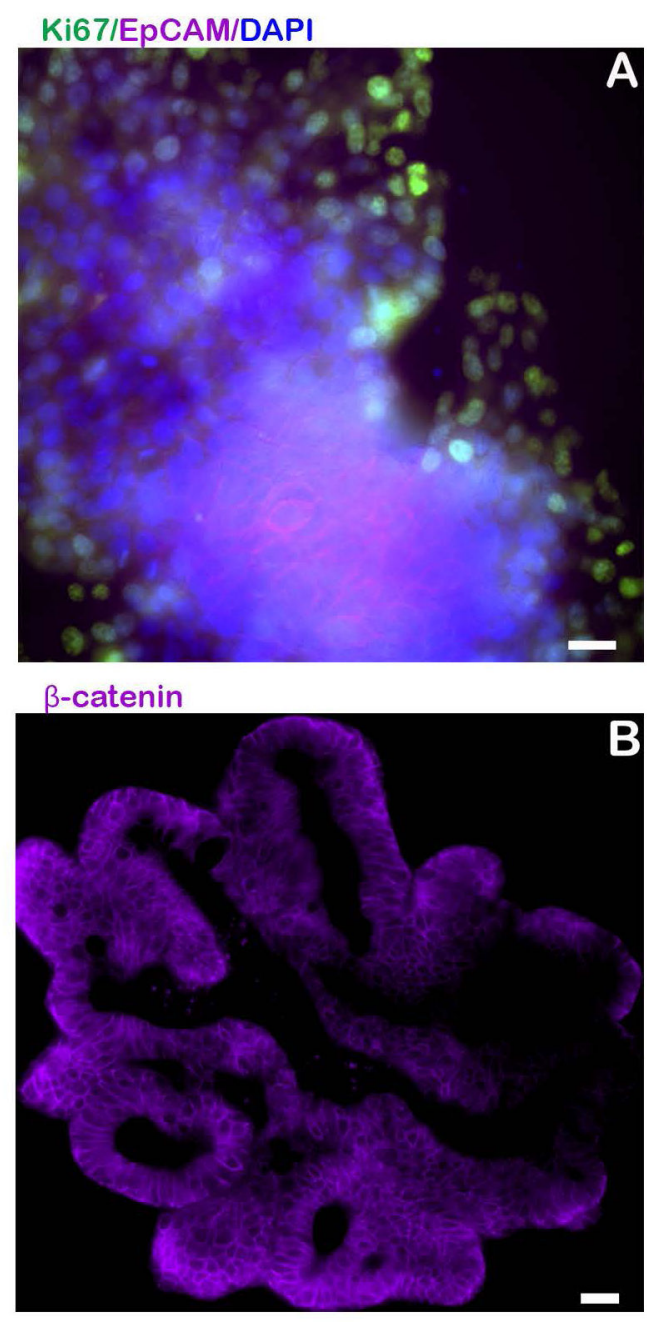

Fig 3.

Detection of epithelial cells. Immunostaining for EpCAM, a pan-epithelial transmembrane protein marker is seen within the centre of an equine enteroid that was whole mounted (panel A). Immunostaining for $\beta$-catenin, a membrane-bound protein, is evident on the cellular border of a sectioned enteroid (panel B). Nuclei, blue. Scale bar $20 \mu \mathrm{m}$. 

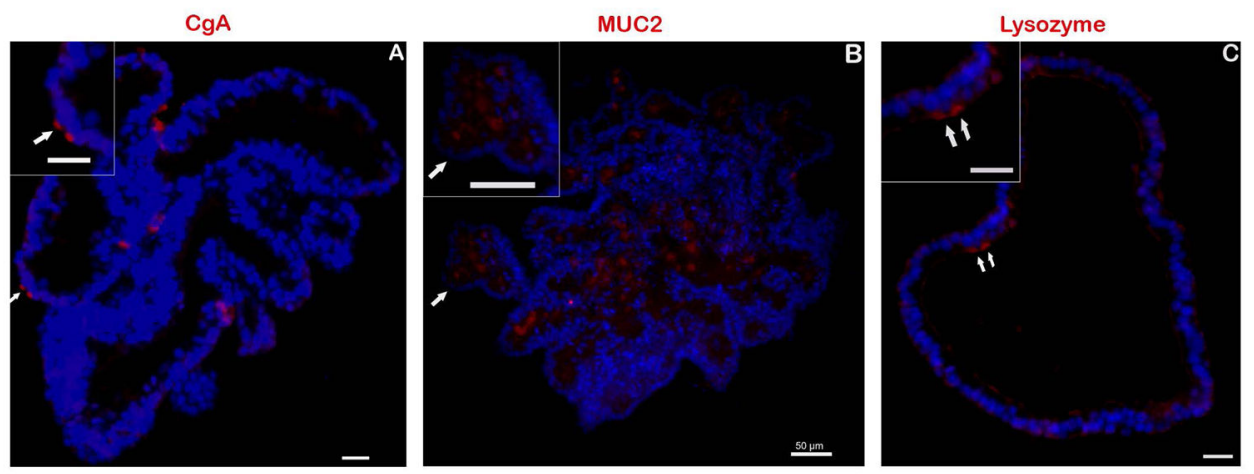

Fig 4.

Markers to identify cell lineages within in vitro cultures. The existence of differentiated, post-mitotic cell lineages was confirmed using biomarkers for identification: anti-CgA (enteroendocrine, panel A), anti-MUC2 (goblet, panel B) and anti-lysozyme (paneth, panel C) antibodies. All specific markers shown in red. Digital magnification of each image provided in the insert. Nuclei, blue. Scale bar $20 \mu \mathrm{m}$ unless noted. 
Table 1

\begin{tabular}{|c|c|c|c|c|}
\hline \multirow{6}{*}{ 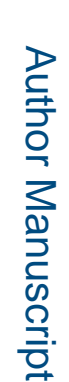 } & \multicolumn{4}{|c|}{ Functional Antibodies Used } \\
\hline & Cell Type & Antibody & Fixation & Dilution \\
\hline & Epithelial & $\begin{array}{l}\text { EpCAM } \\
\text { B-catenin }\end{array}$ & WM & $1: 250$ \\
\hline & Proliferative cell & Mouse anti-human Ki67 & $\mathrm{WM}$ & $1: 100$ \\
\hline & & & $\mathrm{PE}$ & $1: 250$ \\
\hline & Intestinal epithelial stem cell & Rabbit anti-human SOX9 & WM & $1: 500$ \\
\hline & & & $\mathrm{PE}$ & $1: 1000$ \\
\hline & Enteroendocrine cell & Rabbit anti-porcine chromogranin A & WM & $1: 500$ \\
\hline & & & $\mathrm{PE}$ & $1: 1000$ \\
\hline & Goblet cell & Rabbit anti-human MUC2 & $\mathrm{PE}$ & $1: 1000$ \\
\hline & Paneth cell & Rabbit anti-human lysozyme & PE & $1: 500$ \\
\hline
\end{tabular}

$\mathrm{PE}=$ Paraffin embedded $; \mathrm{WM}=$ Whole mount 


\section{Table 2}

PCR Primer Sequences.

\begin{tabular}{|c|c|c|c|}
\hline Target & Forward $\left(5^{\prime}-3^{\prime}\right)$ & Reverse $\left(5^{\prime}-3^{\prime}\right)$ & Product Size (bp) \\
\hline \multicolumn{4}{|c|}{ Active Stem Cell } \\
\hline SOX9 & AACAAGCCTCACGTCAAGCG & TCCGCCTCCTCCACGAAA & 176 \\
\hline LGR5 & AGCCTGGTGGTTCTGCATCT & AACGCTTTCTCGGGGATCAG & 200 \\
\hline \multicolumn{4}{|c|}{ Reserve Stem Cell } \\
\hline$H O P X$ & AGTGGCGGCGGTCGGAA & ACAGTGGCACATACAACACT & 167 \\
\hline$L R I G$ & GGCTGACACAACTGGACCTC & TGGTGCCCGAAATGTCGTTA & 477 \\
\hline \multicolumn{4}{|c|}{ Epithelial Cell } \\
\hline EPCAM & TGACCACAAACTGCTCTGTGA & AGCCCGTCGTTATTCTGGAT & 180 \\
\hline \multicolumn{4}{|c|}{ Absorptive Enterocytes } \\
\hline SIM & GCAATACTGGGGGAAGCAGT & CAGATCCAGCAAAAGTTGACC & 137 \\
\hline \multicolumn{4}{|c|}{ Goblet Cell } \\
\hline MUC2 & AGGACCTGAAGAAGTGCGTC & AGTTGAGAATCTTTCCTTCCTC & 165 \\
\hline \multicolumn{4}{|c|}{ Enteroendocrine Cell } \\
\hline$C G A$ & CTGCGAGGAGATGAACGGAT & AGAACCTCTGCGAGTTCGTC & 143 \\
\hline \multicolumn{4}{|c|}{ Paneth cells } \\
\hline$L Y Z$ & CCTGGTCAGCCTAGAGGTCT & TGGCCAAACAGACCCAGTTT & 186 \\
\hline \multicolumn{4}{|c|}{ Proliferating cells } \\
\hline$P C N A$ & CATGGACTCGTCCCACGTC & CTTCAGCCCTTAGGGTAATG & 164 \\
\hline \multicolumn{4}{|c|}{ Housekeeping Gene } \\
\hline$B-A C T I N$ & CTGTGGCATCCACGAAACTA & GACAATGAGGCCAGAATGGA & 237 \\
\hline
\end{tabular}

Equine Vet J. Author manuscript; available in PMC 2019 March 01. 